\title{
Recycled Old Corrugated Container Fibers for Wood-Fiber Cement Sheets
}

\author{
Divino Eterno Teixeira \\ Forest Products Laboratory (LPF), Brazilian Forest Service (SFB), 70818-900 Brasília, DF, Brazil \\ Correspondence should be addressed to Divino Eterno Teixeira, divinot@gmail.com
}

Received 19 January 2012; Accepted 11 February 2012

Academic Editors: F. Castedo-Dorado and S. Yildiz

Copyright ( 2012 Divino Eterno Teixeira. This is an open access article distributed under the Creative Commons Attribution License, which permits unrestricted use, distribution, and reproduction in any medium, provided the original work is properly cited.

Recycled pulp of old corrugated containers (OCCs) was studied as a possible fiber source for wood-fiber cement (WFC) sheets. This industry currently largely relies on kraft pulp, an expensive fiber source. Thus, WFC sheets were made using less costly OCC fibers utilizing various types of treatments including fiber fractionation (FF) and refining to 500 and 400 Canadian Standard Freeness (CSF) to determine the effect of these treatments on the sheets strength. Unprocessed virgin kraft fiber of radiata pine (Pinus radiata) was used as control for comparison purposes. The unprocessed OCC pulp furnish yielded an initial freeness of 635 CSF; after fractionating, however, it was increased to 754 CSF. OCC pulp presented a kappa number of 47 , compared to 23.7 for $P$. radiata. Fractionating OCC pulp was effective in raising the range of long fibers in the stock from 68 percent to 85 percent, before and after fractionating, respectively. Results from WFC sheets made in laboratory showed that there was no significant difference in board strength among boards made with unprocessed OCC fibers, fractionated and refined OCC, and P. radiata fibers. However, sheet strength decreased when refined OCC fibers were used. The results suggest that OCC fibers can produce WFC sheets with desirable characteristics compared to those of unrefined virgin kraft fiber of $P$. radiata.

\section{Introduction}

Wood-fiber cement (WFC) composites have recently become well accepted in the United States for a range of uses, such as roof tiles and siding, where wood and other materials were traditionally used [1]. World demand for products derived from inorganic-bonded wood and fiber materials, of which WFC sheet is a part, in general, is estimated to rise over the next years $[1,2]$. The potential for using recycled fibers in these products is high and it could be an attractive option with the development of fiber fractionation [3], which appears to improve fiber properties for these types of products. Significant price swings and generally the high cost for pulp mandate a search for cost-effective and stable fiber supply options for WFC sheets and other fiber cement products. The use of recycled old corrugated containers (OCCs) can be economical as well as environmentally attractive.

Fiber attributes such as fiber length, fiber-to-mass ratio, fiber substitution level, and level of fiber refinement are important parameters in determining desirable WFC product properties. Available literature reports the use of virgin and recycled newsprint fibers [4-8]. A small amount of information is found regarding the use of recycled containers and the effect of fiber fractionating on the properties of WFC sheets.

\section{Background}

The first fiber-cement sheet manufactured was a composite of cement and asbestos fibers produced by the Hatschek process [1]. Successful manufacturing of asbestos-cement products is related to the stability of asbestos fibers in the alkaline environment of cement, among other factors. Asbestos fiber cement products are still manufactured in many parts of the world. However, the production of such products is gradually declining worldwide due to health concerns. As a result, environmental and health concerns have encouraged the development of asbestos-free cementitious 
products. As a result, a variety of papers were published relating the use of different sources of natural fibers, such as coir (Cocus nucifera), bagasse, bamboo, babaçu coconut (Orbignya sp.), rice and wheat straw, sisal (Agave sisalana), and others, replacing asbestos in cement bonded panels [2, 9-15]. The use of fibers from wood species has become a viable alternative to asbestos fibers. As a result, such fibers are now increasingly replacing asbestos in the production of fiber-cement panels in the industrialized nations. Wood pulp characteristics have a significant influence on the properties of WFC products. Such pulp parameters as kappa number, fiber length or classification, freeness, refining, or beating, among others, are controllable properties affected by the pulp preparation. These parameters can be measured in accordance with procedures developed by the pulp and paper industry [16-19].

Corrugated container paper is composed of two different materials: the corrugated core sheet of paperboard and the flat paper cover (linerboard). The former is a corrugated medium produced by a semichemical process with pulp yields ranging from 55 to 90 percent of dry wood input [20]. A kraft process with low pulp yields of approximately 45 percent forms the linerboard. It is an unbleached kraft linerboard paper with high strength and identified by its brown color [20]. A sheet of corrugated container can have different compositions of the corrugated medium and linerboard layers varying from unlined to double-faced, double-doubled, or triple-walled corrugated cardboard [20]. In North America, corrugated containerboard is made of $1 / 3$ corrugated medium and 2/3 kraft linerboard.

Pulp kappa number is a measure of lignin content remaining in the stock after cooking. The higher the kappa number, the higher the amount of lignin available in the furnish [18]. Freeness represents the resistance that the pulp stock offers on draining water added to it. It gives an indication of the level of refining and quality of the pulp stock. In North America, the Canadian Standard Freeness (CSF) test is the most prevalent method for measuring pulp freeness $[17,20]$. Fiber subjected to refining exposes its fibrils to the mechanical action of a beater device or a PFI mill. The refining level of a pulp stock aims to achieve a certain freeness level, which is accomplished by the number of revolutions used in the refiner. Pulp freeness decreases as the refining level increases $[19,20]$.

WFC sheet is a product that uses Portland cement, silica sand, pozzolans, water, and wood fiber, which serves as the reinforcement. It combines the desirable characteristics of cement and wood fiber giving the sheet high fire and water resistance, elasticity, strength, resistance to attack by fungus and termites, and resistance to weathering $[1,2,8-15,21-$ 30]. Most recently, wood strand cement-bonded boards have been developed $[23,27,28,31-33]$. However, fibers from recycled wood sources continue to have an attraction due to their favorable price and availability. Pulp fibers whether from virgin or recycled sources serve, among other considerations, as reinforcing material to combat cement cracking in fiber-cement products. Fibers also increase toughness and the cracking resistance of the product, which are important considerations in such application as siding and roofing $[1,8]$. Fibers produced by kraft process are generally used for commercial thin sheet production, with the principal wood source being softwood fiber. In prior research, recycled wastepaper fibers were mixed with kraft pulp yielding viable products [5].

The potential market for recycled cellulose fibers for WFC products is large because this industry is likely to gradually replace asbestos fibers with cellulose fibers in many developing countries around the world over the coming years. An estimated 1100 flat sheet-manufacturing facilities are currently operating, most of which still use asbestos as the source of fiber. Wastepaper fibers, sludge, and other recycled sources of pulp materials are already used in cement-bonded products $[4,5,7,20]$.

\section{Objectives}

The overall objective of this project was to evaluate the physical and mechanical properties of wood-fiber reinforced cement sheets using fibers from recycled old corrugated containers (OCCs) in unprocessed form and after fiber treatments by refining and fractionating. One specific objective was to determine a variety of attributes for OCC fibers and compare these data with those for radiata pine (P. radiata), since the latter have been a preferred fiber source by the industry. The percentage (by weight) of fibers retained on each screen used, freeness, kappa \# and amount of lignin of the fiber were examined. Furthermore, it was an objective of this project to assess the mechanical and physical properties of WFC sheets made using the untreated and treated fibers.

\section{Materials and Methods}

4.1. Pulp Preparation. OCC sheets were soaked in water for a minimum of 5 hours prior to disintegration, which was performed using a TMI disintegrator at 15,000 revolutions. The number of revolutions was selected so that no fiber clumping was to occur after disintegration. The fibers, upon disintegration, were dewatered in a Buchner funnel to about 20 percent consistency and the "pad" was stored in a refrigerator to avoid decomposition. The stock was divided into two categories: one without processing (untreated) and another to be fractionated and refined (treated).

Corrugated pulp bales of unbleached kraft $P$. radiata were cut to smaller sizes, soaked in water for 24 hours, and disintegrated at 25,000 revolutions. Furthermore, they were dewatered and stored in a refrigerator. $P$. radiata pulp was used without processing (untreated). The average fiber lengths, measured only for the unprocessed stocks, were $1.56 \mathrm{~mm}$ for the OCC fibers and $2.6 \mathrm{~mm}$ for fibers from $P$. radiata.

4.1.1. Fiber Fractionating (FF) and Refining. The OCC fibers were fractionated using a Bauer-McNett classifier. Fiber loads of 30 grams were diluted in water to 0.2 percent consistency and introduced into the classifier. Classification time was set to 10 minutes and the fibers retained on the +14 , +25 , and +50 mesh screens were collected, weighted, and 
grouped for use in making the WFC sheets. The remaining fibers from screen mesh sizes $+100,+200$, and -200 (fines) were discarded.

The OCC fibers were classified to determine the percentage by weight of fibers retained on each screen used before and after fiber fractionation. Three replications were run for each fiber type thus fractionated. The procedure used was according to TAPPI T 233 standard [16] with the exception that 5-gram loads were used instead of that recommended by the standard. Pulp of $P$. radiata was also classified.

Refining was carried out on unprocessed as well as fractionated OCC fiber stock. A PFI mill was used to refine the fibers to the desired freeness of 500 and 400 CSF [16]. A PFI mill curve provided the number of revolutions necessary to achieve each target freeness according to TAPPI T 248 [17] Standard.

4.1.2. Fiber Freeness. Freeness of the various pulps was determined at each processing level. A freeness testing apparatus was used according to TAPPI T 227 standard [17].

4.1.3. Fiber Kappa Number and Lignin Content. The procedure for the $k$ number $\left(k^{\#}\right)$ test was conducted in accordance with TAPPI T 236 standard [18]. Kappa number (kappa \#) of the OCC fiber was calculated by using (1). The amount of lignin that remains in the pulp furnish after cooking by the kraft process is found by multiplying the kappa \# times 0.13 [18]:

$$
\text { kappa \# }=1.67 k^{\#}-4.2 \text {. }
$$

4.2. WFC Sheets Making. In this project, two types of fiber treatments were utilized in making WFC sheets. Some of the OCC fibers used were those without any processing, while others were OCC fibers fractionated and classified. The sheets measuring $305 \times 254 \times 10 \mathrm{~mm}$ were prepared using a slurry/vacuum-dewatering process. The fibers, upon disintegration, were first mixed (in a fiber-to-mass ratio of 10 percent) with tap water to a consistency of 20 percent. Next, commercially available kaolin clay, fine silica sand, and ordinary Portland cement were mixed, in this order, for a total of 5 minutes (kaolin clay/Portland cement/silica sand ratio of $0.1 / 0.7 / 1.0)$. The consistency of the slurry was reduced to 16 percent for better formation and vacuum pressure application. The slurry was then poured into an aluminum box and vacuum applied to remove excess water. After dewatering, the mat was pressed to $0.7 \mathrm{MPa}$ for 15 minutes to a target density of $1.2 \mathrm{~g} / \mathrm{cm}^{3}$. Finally, the board was released from the press and sealed in a plastic bag for five days, followed by conditioning and curing for 28 days. Conditioning environment involved 35 percent relative humidity $(\mathrm{RH})$ and $23^{\circ} \mathrm{C}$. Testing was performed after curing. The same process was accomplished in producing the sheets with the fibers of $P$. radiata, used as control. Three replications were made for each treatment and the control, totaling 21 sheets.
4.3. WFC Sheets Testing. The panels were tested for threepoint flexural strength in bending (modulus of ruptureMOR and modulus of elasticity-MOE) (saturated and conditioned), water absorption-WA, thickness swelling-TS, and linear variation-LV, according to ASTM D1037 [34]. The flexural strength test was performed on a model 1137 Instron universal testing machine. Specimens for the linear expansion test were $231.8 \mathrm{~mm}$ length and $50.8 \mathrm{~mm}$ width. One sample per board was tested between 30 and 90 percent $\mathrm{RH}$ conditions. The density and moisture content of the panels were determined as well. Two samples each were used for MOR and MOE testing, four otherwise.

4.4. Experimental Design. The statistical analysis was conducted in two steps. The effect of each treatment was studied in an analysis of variance (ANOVA) for the physical and mechanical tests.

In the first analysis, a test comparison of means among the treatments (sheets of OCC fibers) and the control (sheets of $P$. radiata fibers) was conducted using Dunnett's multiple comparison test. In this analysis, a total of 21 sheets were included.

In the second analysis, a comparison using the RyanEinot-Gabriel-Welsch (REGWQ) multiple range test was conducted to detect means differences among the treatments of OCC fiber sheets only, excluding the control. A completely randomized factorial design (CRF-23) was used to test differences among the treatments including two levels of fiber types and three levels of refinement. This analysis included a total of 18 sheets.

A SAS [35] statistical program was used for statistical analyses. The alpha used for both tests was 0.05 (95\% confidence level). The treatments of fiber refining and fiber fractionating were assessed as follows:

Treatments:

(1) fiber type:

(1.1) OCC fibers as received (unprocessed): OCC,

(1.2) OCC fibers after fiber fractionating: OCC/FF,

(2) fiber refinement level (Canadian Standard Freeness$\mathrm{CSF})$ :

(2.1) unrefined (initial freeness),

(2.2) refined to $500 \mathrm{CSF}$,

(2.3) refined to $400 \mathrm{CSF}$,

(3) control: unbleached kraft fiber from $P$. radiata (unprocessed).

\section{Results and Discussion}

5.1. Fibers Processing. The results of tests conducted on initial freeness, kappa \#, lignin content, and $\mathrm{pH}$ of fibers used are presented in Table 1. As expected, $P$. radiata presents a low concentration of lignin (3.1\%) expressed by a lower kappa number of 23.7. OCC pulp contains a higher kappa number of 47 and, consequently, higher lignin content $(6.1 \%)$. It is 
TABLe 1: Results of initial freeness, kappa \#, lignin content, and $\mathrm{pH}$ for OCC unprocessed and after fiber fractionating (OCC/FF) in comparison with radiata pine pulp.

\begin{tabular}{lccc}
\hline Test & \multicolumn{3}{c}{ Pulp type } \\
& OCC & OCC/FF & R. Pine \\
\hline Initial freeness (CSF) & 635 & 754 & 730 \\
kappa \# & 47 & 47 & 23.7 \\
Lignin content (\%) & 6.1 & 6.1 & 3.1 \\
Fiber pH & 6.6 & 6.6 & 7.5 \\
\hline
\end{tabular}

formed by a mix of furnish from chemical and semichemical kraft processes and therefore contains a larger amount of lignin.

Results of the fiber fractionating performed in the BauerMcNett classifier for unrefined OCC fibers, and after fiber fractionating the same fibers, compared with $P$. radiata pulps are shown in Figure 1. These results reproduce the average of three samples examined for each fiber type or processing. The pulp of $P$. radiata has an impressive amount of long fibers retained on screens 14 to 50 mesh (92.3\%) and only about 7.7 percent were lost as fines. Compared with $P$. radiata, OCC fibers had 32.1 percent and 15.5 percent of fines, before and after fractionating, respectively. This indicates that fiber fractionation of the OCC pulp was effective in increasing the range of long fibers from 68 percent to about 85 percent in the stock. It is also reflected in the freeness of the pulp, which was raised from 635 (initial) for OCC fibers as received to 754 for the same pulp after fractionating.

Results of the PFI mill test for each fiber type are shown in Figure 2. From this figure, the number of revolutions necessary to refine to 500 and $400 \mathrm{CSF}$ was assessed. The unprocessed OCC fiber can be more easily refined when compared with same fibers after fractionating. Only 700 and 2,180 revolutions were required in order to refine it to 500 and $400 \mathrm{CSF}$, respectively. After fractionating, 4,100 and 5,800 revolutions were required for refining to the same freeness values aforementioned, respectively. $P$. radiata pulp required more revolutions $(9,300$ and 11,500$)$ to achieve the same freeness levels.

5.2. WFC Sheets Testing. The outcome of physical and mechanical testing obtained from the OCC WFC sheets is presented in Table 2. Figures 3 and 4 give a better understanding of the results.

The results are suitable to standard of cement-bonded panels [36] and to commercially available Cetris [37], Bison Panel [38], and Versaroc [39] cement-bonded particleboards.

The sheets MOR in the dry condition ranged from 4.34 to $11.42 \mathrm{MPa}$, respectively, for OCC sheets refined to $400 \mathrm{CSF}$ (OCC/400) and OCC fractionated and refined to $400 \mathrm{CSF}(\mathrm{OCC} / \mathrm{FF} / 400)$. The OCC sheets without any treatment showed MOR of $10.95 \mathrm{MPa}$. These values are equal or superior to WFC sheets reported in the literature using fibers from wastepaper. Fuwape et al. [6] used wastepaper

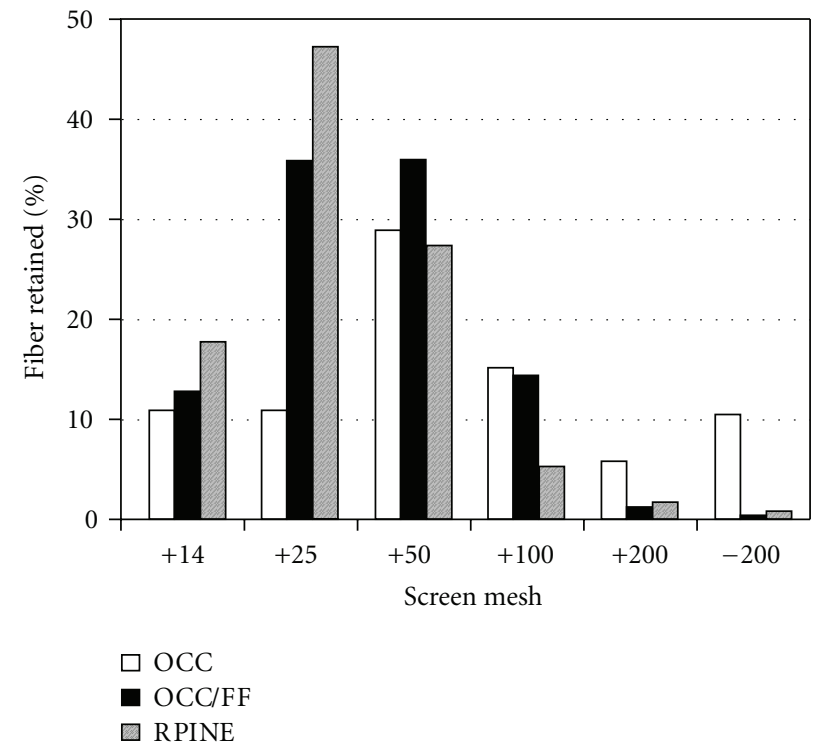

Figure 1: Results of the fiber fractionating performed using the Bauer-McNett classifier for the OCC pulp unprocessed, after fiber fractionating (OCC/FF), and for radiata pine (RPINE).

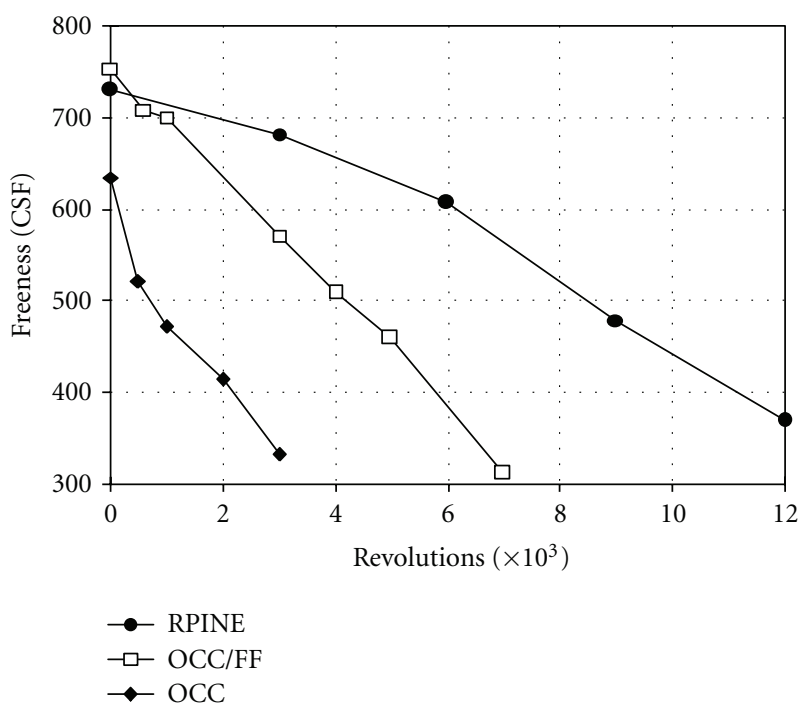

FIGURE 2: PFI mill refining test for the OCC pulp unprocessed, after fiber fractionating (OCC/FF), and for radiata pine (RPINE).

and sawdust and obtained MOR ranging from 4.85 to 11.69 MPa. Goroyias et al. [7] obtained 11.9 MPa using sludge. Fiber of coir (Cocus nucifera) was used to produce cement-bonded boards by Ferraz et al. [14] with MOR of 3.78 MPa.

MOE in the dry condition ranged from 1.35 to $3.72 \mathrm{GPa}$ also for OCC/400 and OCC/FF/400, respectively, while Fuwape et al. [6] obtained reported MOE values ranging from 2.80 to $5.57 \mathrm{GPa}$. Ferraz et al. [14] reported maximum MOE of $1.15 \mathrm{GPa}$.

Regarding MOR, the results showed that sheets made with unprocessed OCC fibers and with the same fibers 
TABLE 2: Results of physical and mechanical tests of wood-fiber cement sheets.

\begin{tabular}{|c|c|c|c|c|c|c|c|c|}
\hline \multirow{4}{*}{ Treatment } & \multicolumn{8}{|c|}{ Properties } \\
\hline & \multicolumn{2}{|c|}{$\mathrm{MOR}^{1}$} & \multicolumn{2}{|c|}{ MOE } & \multirow{2}{*}{ WA } & \multirow{2}{*}{ TS } & \multirow{2}{*}{ LV } & \multirow{2}{*}{ Density } \\
\hline & (Dry) & (Wet) & (Dry) & (Wet) & & & & \\
\hline & $(\mathrm{MPa})^{2}$ & $(\mathrm{MPa})$ & $(\mathrm{GPa})$ & $(\mathrm{GPa})$ & (\%) & (\%) & $(\%)$ & $\mathrm{g} / \mathrm{m}^{3}$ \\
\hline OCC & $10.95^{\mathrm{a}}(1.75)$ & $3.73^{\mathrm{b}}(.09)$ & $3.59^{\mathrm{ab}}(.12)$ & $2.01^{\mathrm{a}}(.16)$ & $31.8^{c}(1.91)$ & $0.29^{\mathrm{bc}}(.09)$ & $0.0^{\mathrm{b}}(.06)$ & $1.15^{\mathrm{a}}(.02)$ \\
\hline OCC/500 & $4.83^{c^{*}}(.71)$ & $2.34^{\mathrm{dc} \mathrm{c}^{*}}(.54)$ & $1.66^{\mathrm{d}^{*}}(.13)$ & $1.09^{\mathrm{bc}^{*}}(.47)$ & $39.2^{\mathrm{b}^{*}}(3.08)$ & $0.78^{\mathrm{b}}(.3)$ & $0.028^{\mathrm{b}}(.02)$ & $1.16^{\mathrm{a}}(.04)$ \\
\hline OCC/400 & $4.34^{c^{*}}(.13)$ & $1.65^{\mathrm{d}^{*}}(.36)$ & $1.35^{\mathrm{d}^{*}}(.03)$ & $0.59^{c^{*}}(.04)$ & $44.6^{\mathrm{a}^{*}}(3.15)$ & $4.29^{4 \mathrm{a}^{*}}(.22)$ & $0.17^{\mathrm{a}^{*}}(.05)$ & $1.13^{\mathrm{a}}(.03)$ \\
\hline OCC/FF & $6.64^{\mathrm{bc}^{*}}(1.26)$ & $2.93^{c^{*}}(.17)$ & $2.45^{c^{*}}(.59)$ & $1.47^{\mathrm{ab}^{*}}(.29)$ & $36.6^{\mathrm{bc}}(1.24)$ & $0.36^{\mathrm{bc}}(.12)$ & $0.021^{\text {b. }}(.03)$ & $1.11^{\mathrm{a}}(.04)$ \\
\hline OCC/FF/500 & $9.46^{\mathrm{ab}}(1.55)$ & $4.54^{\mathrm{a}}(.05)$ & $2.92^{\mathrm{bc}^{*}}(.40)$ & $2.29^{\mathrm{a}}(.44)$ & $33.7^{\mathrm{bc}}(.87)$ & $0.22^{c}(.13)$ & $0.024^{\mathrm{b}}(.01)$ & $1.14^{\mathrm{a}}(.01)$ \\
\hline $\mathrm{OCC} / \mathrm{FF} / 400$ & $11.42^{\mathrm{a}}(1.87)$ & $4.42^{\mathrm{ab}}(.32)$ & $3.72^{\mathrm{a}}(.22)$ & $2.33^{\mathrm{a}}(.36)$ & $33.7^{\mathrm{bc}}(1.41)$ & $0.23^{\mathrm{c}}(.29)$ & $0.002^{\mathrm{b}}(.04)$ & $1.13^{\mathrm{a}}(.03)$ \\
\hline RPINE $^{3}$ & $11.95(2.61)$ & $4.36(.97)$ & $3.71(.33)$ & $2.34(.36)$ & $33.5(2.48)$ & $0.28(.54)$ & $0.004(.03)$ & $1.14(.04)$ \\
\hline Requirement ${ }^{5}$ & $9.0(\mathrm{~min})$ & - & $3.0(\mathrm{~min})$ & - & - & $1.5(\max )$ & - & 1.25 \\
\hline
\end{tabular}

Means within a column followed by the same capital letter are not significantly different at 95 percent C.L. using the REGWQ $F$ test. Means with an asterisk are significantly different from control at 95 percent C.L. using Dunnett's test for comparing means with a control. Numbers in parenthesis are standard deviations. Means are average of 3 replications.

${ }^{1}$ MOR: Modulus of Rupture; MOE: Modulus of Elasticity; WA: Water Absorption; TS: Thickness Swelling; LV: Linear Variation with change in moisture content (from 30 to $90 \%$ RH). ${ }^{2} 1 \mathrm{MPa}: 10.2 \mathrm{~kg} / \mathrm{cm} ; 1 \mathrm{GPa}: 10.2 \times 10^{3} \mathrm{~kg} / \mathrm{cm}^{2} .{ }^{3}$ Control. ${ }^{4}$ Samples with delamination. ${ }^{5} \mathrm{BISON}$ DIN [36].

fractionated and refined to $500(\mathrm{OCC} / \mathrm{FF} / 500)$ and $400 \mathrm{CSF}$ (OCC/FF/400) do not differ from the control (RPINE) at 95 percent confidence level according to Dunnett's test [35]. Upon refining, OCC pulp yielded panels with low strength. OCC pulp (unprocessed) contained short fiber lengths, averaging $1.56 \mathrm{~mm}$, compared with $P$. radiata, averaging $2.6 \mathrm{~mm}$. OCC pulp also contained a fairly large amount of fines, 35 percent. The refining process causes fiber shortening and generates additional fines $[20,40]$. This process can increase fines in excess beyond the optimum limit for making WFC sheets with desirable properties. An excess of fines does not contribute much to board strength but acts more as filler [30]. Fiber fractionating, on the other hand, increases the percentage by weight of long fibers and decreases the amount of fines [3]. Therefore, fractionating leaves more room for fines generated during refining yet maintains a desirable amount of longer fibers above the critical value required for WFC sheets. This explains the differences in sheet properties made with corrugated fiber before and after fiber fractionating. Unfractionated OCC fibers produce sheets with strengths that decrease as the level of refining increases (Figure 3). However, the strength of sheets made with fractionated and refined fibers increases proportionally with the refining level.

All treatments, including the control, lose strength when the sheets are saturated in water and then tested for MOR. This is consistent with the reduction in flexural strength of 47 to 75 percent of the dry strength reported by [5]. An increase in the moisture content of the samples causes the fiber-tofiber bond strength to decrease as the hydrogen bonds are replaced with water.

WFC sheets made with OCC fibers and OCC/FF/400 fibers were different from the other treatments at 95 percent confidence level and showed comparable strengths by the Ryan-Einot-Gabriel-Welsch (REGWQ) test of means for
MOR at dry condition. Boards made with OCC/FF/500 fibers yielded the best MOR values for the saturated samples. OCC fibers $\mathrm{OCC} / \mathrm{FF} / 500$, and $\mathrm{OCC} / \mathrm{FF} / 400$ had strengths values comparable to the control values using Dunnett's test. Sheets made with $\mathrm{OCC} / \mathrm{FF} / 400$ fiber exhibited the higher elasticity values followed by those made with OCC and OCC/FF/500 fibers, in that order. Decreases in MOE from the dry to the saturated test were in the range of 21 to 56 percent.

WFC sheets made with OCC fibers refined to 500 CSF (OCC/500) and to 400 CSF (OCC/400) showed higher water absorption than the control, as measured by Dunnett's test [35]. According to results from the REGWQ test, sheets made with OCC fibers showed the lowest water absorption (31.8\%) and were statistically different from other sheets. OCC/400 was the maximum water absorption (44.6\%). These values are lower than the WA reported, at the similar density, by Erakhrumen et al. [13] (54\%), but higher than some WFC with wood fibers [41]. There was no significant difference among the sheets made with recycled fibers fractionated (OCC/FF), OCC/FF/500, and OCC/FF/400 fibers (Figure 4).

The sheets with OCC/400 showed also very high thickness swelling (4.29\%). Further examination of the samples exhibiting such high thickness swelling revealed the presence of delamination lengthwise. Delamination occurred along the line where two layers of material were jointed during the mat forming process. Delamination was not found in samples from other treatments. All the remaining treatments presented low TS under $1 \%$. Other authors reported higher TS: $2.9 \%$, Erakhrumen et al. [13]; $3.55 \%$ to $12.3 \%$, Fuwape et al. [6]; $1.49 \%$, Silva et al. [41]; and 1.6\%, Ferraz et al. [14]. When the sheets made with corrugated fibers are compared with data for the control samples, panels made with OCC/400 are significantly different from those using $P$. radiata. The low-dimensional stability of sheets made with refined OCC fibers appears to be due to the increase 


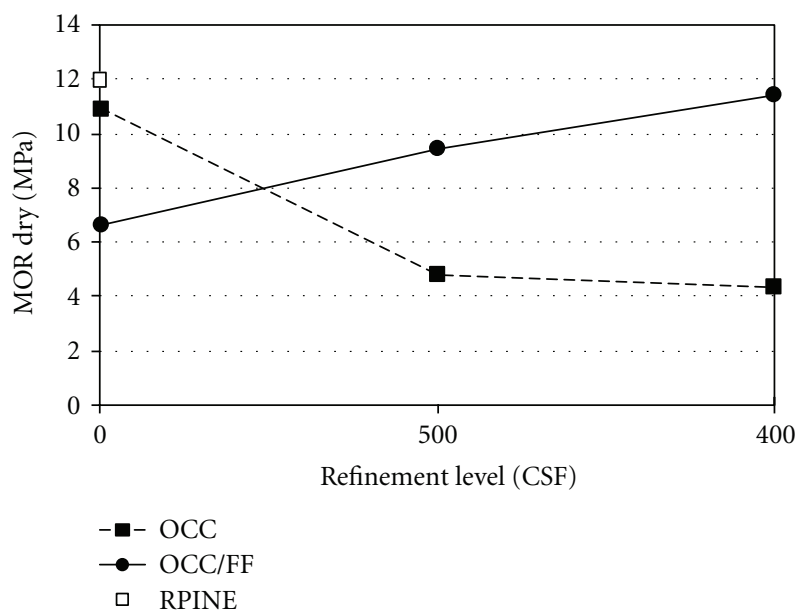

(a)

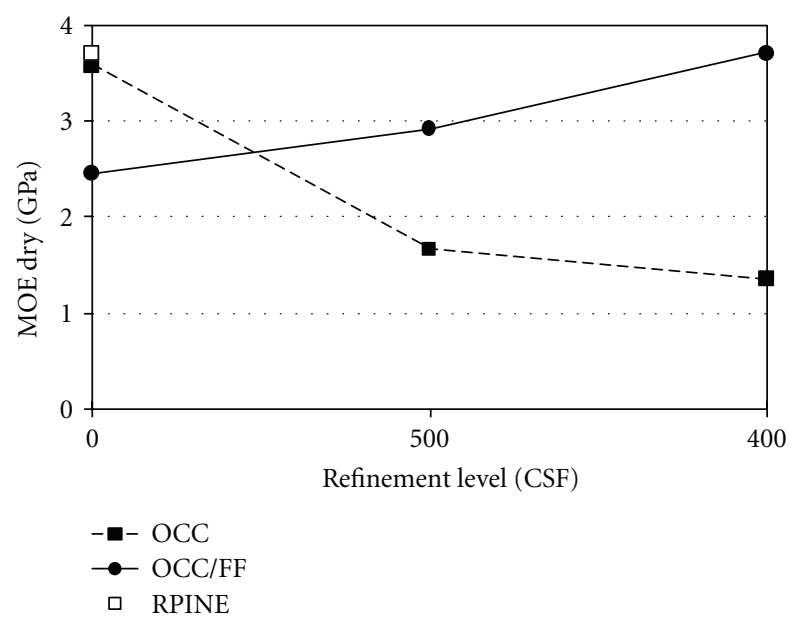

(b)

FIGURE 3: Mechanical properties (dry condition) of the WFC sheets.
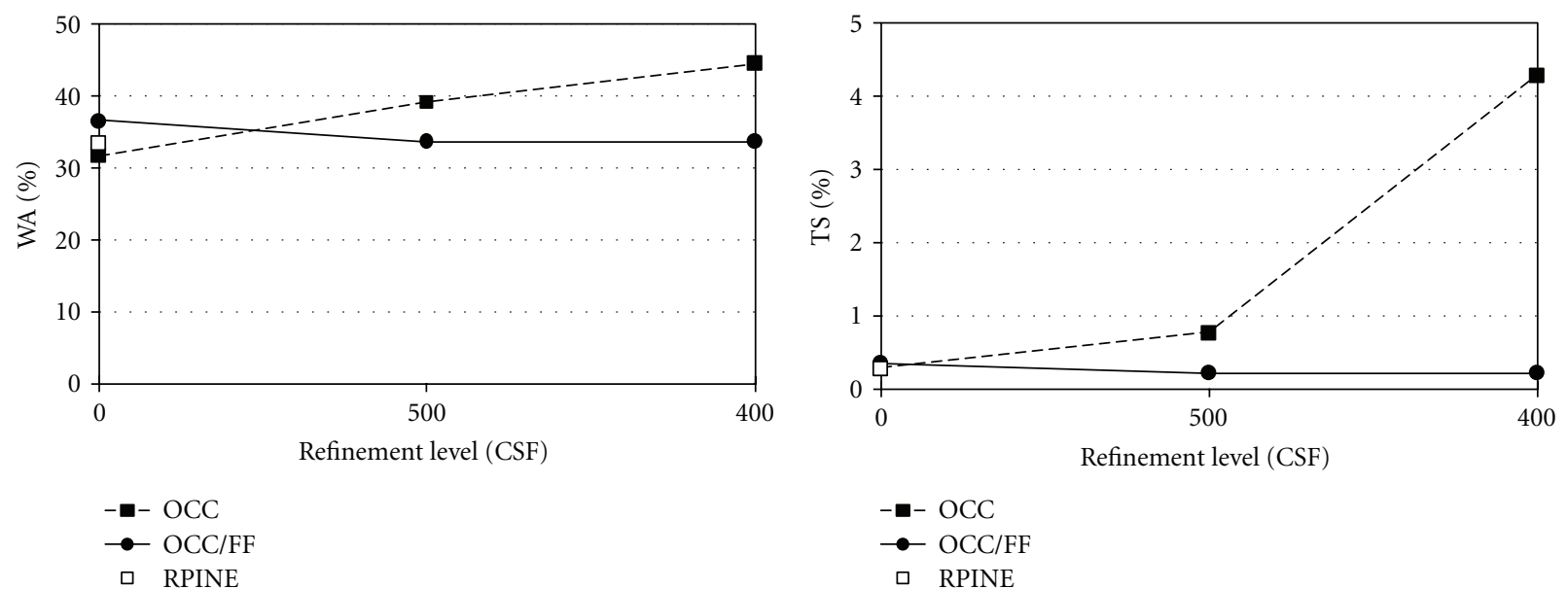

(a)

(b)

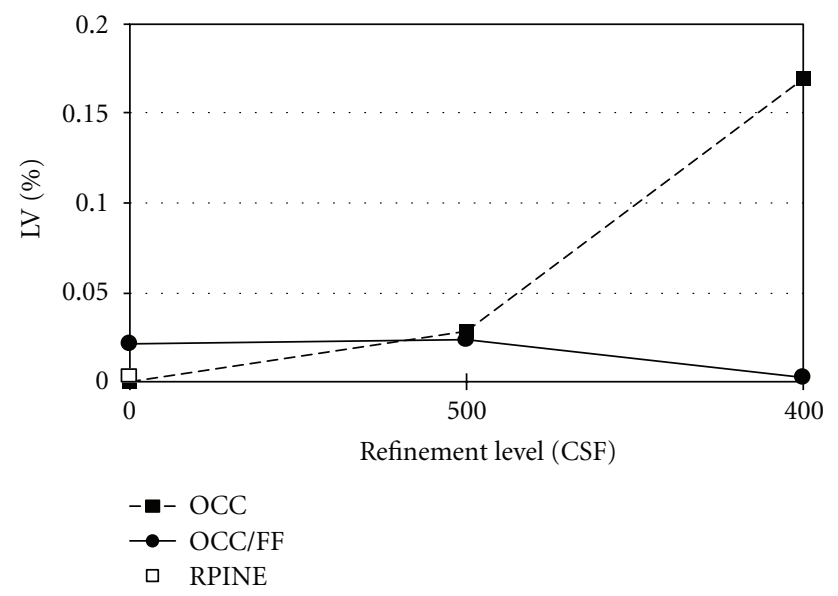

(c)

FIGURE 4: Physical properties of the WFC sheets. 
in the amount of fines, as discussed earlier. This can be visually noted when comparing results between sheets using unprocessed OCC fibers and those using the same fibers but after refining to $500 \mathrm{CSF}$ (Figure 4). In this case, thickness swelling increased 170 percent. The fiber shortening and excess of fines cause a very large increase in the surface area of the fibers and a loss in their bonding potential [20], even though a certain percentage of long fibers is maintained. This effect is minimized for refined OCC fibers after fiber fractionation because the pulp stock starts with a smaller amount of fines when the refining is carried out.

Following the pattern of thickness swelling behavior, sheets made with OCC fibers treated to the higher refinement level (OCC/400) showed the higher linear variation in length $(0.17 \%)$ with change in moisture content (Figure 4$)$. According to Dunnett's test, only this treatment differed from the sheets made with $P$. radiata (control). The remaining treatments presented very low LV ranging from $0 \%$ to $0.028 \%$. The REGWQ test, excluding the control, showed that there is no significant difference among the treatments using OCC fiber, except for the OCC/400.

There was no significant difference in the density of the sheets in this study, meaning that the mixing and forming processes developed produced consistent results in density.

\section{Conclusions}

OCC fibers presented a higher lignin content compared with $P$. radiata, which has been the preferred raw material for manufacturing WFC sheets. Fibers from recycled OCC can be easily refined; therefore less energy is likely needed in the process compared with refining of $P$. radiata pulp. If refining of pulp is required for WFC sheet manufacturing, the results achieved in this project are encouraging because refinement can be easily accomplished either before or after fractionating.

Fractionating OCC fibers was effective in increasing the percentage of long fibers from 68 to 85 percent. Length of fiber is an important attribute for developing higher strength WFC sheets. Secondary fiber from OCC either unprocessed or after fiber fractionating and/or refining can be used to produce sheets with properties comparable in important properties to those made with unbleached kraft fiber of $P$. radiata under air curing conditions used in this study. The results obtained in this project were comparable to or better than those previously reported using wastepaper at the same level of density and also to some commercially available cement-bonded particleboards.

WFC sheets made with OCC pulp presented reduced linear variation with change in moisture content. There appears to be no need to fractionate and/or refine the OCC pulp for sheets production. Additional processing of pulp used in the present study gave board properties that were comparable to those of sheets made with unprocessed OCC fibers. Refining OCC fibers did not contribute to board strength; in fact, it reduced MOR and MOE values by approximately half and increased water absorption, thickness swelling, and linear variation. This conclusion should not be generalized and holds only for the variables and formulation tested in the current study. Changes in these components could lead to different results.

The sheets produced in this study were sensitive to moisture variations and showed a considerable drop in flexural strength from the conditioned state to the saturated test, which is probably due to a reduction in the fiber-tomatrix bond strength. This is similar to results obtained in prior studies.

\section{Recommendations}

Additional studies using recycled OCC fibers should focus on variations in the fiber-to-mass ratio as well as in cementto-silica sand ratios. Use of an autoclave for curing the panels at the higher silica sand/cement ratio could also be of interest because higher silica sand content usually improves sheet properties. It is also important to assess the resiliency of OCC fibers to exposure to autoclave conditions. Data on water absorption suggest that the fiber-to-mass ratio of 10 percent is probably the upper limit for fiber use for obtaining desirable WFC sheets and compatibility with current manufacturing conditions.

Clearly, conclusions drawn in the present study must first be confirmed on pilot scale production before wide-scale applications can be achieved.

\section{Acknowledgements}

The author would like to acknowledge Prof. Al Moslemi (In memoriam), Professor Emeritus at University of Idaho and author's advisor, for his efforts and expertise at the moment of completion of this research.

\section{References}

[1] A. Moslemi, "Technology and market considerations for fiber cement composites," in Proceedings of the 11th International Inorganic Bonded Fiber Composites Conference (IIBCC '08), Madrid, Spain, November 2008.

[2] S. Frybort, R. Mauritz, A. Teischinger, and U. Müller, "Cement bonded composites-a mechanical review," BioResources, vol. 3, no. 2, pp. 602-626, 2008.

[3] R. J. DeFoe, "Optimal refining conditions for development of OCC pulp properties,” TAPPI Journal, vol. 76, no. 2, pp. 157$161,1993$.

[4] J. A. G. O. Alda and J. A. Torrea, "Applications of recycled paper mills effluents to wood substitute products (RESPRO): executive Summary," Oppidium, Universidad SEK, no. 2, pp. 381-398, 2006.

[5] R. S. P. Coutts, "Wastepaper fibres in cement products," International Journal of Cement Composites and Lightweight Concrete, vol. 11, no. 3, pp. 143-147, 1989.

[6] J. A. Fuwape, J. S. Fabiyi, and E. O. Osuntuyi, "Technical assessment of three layered cement-bonded boards produced from wastepaper and sawdust," Waste Management, vol. 27, no. 11, pp. 1611-1616, 2007.

[7] G. Goroyias, R. Elias, and M. Fan, "Research into using recycled waste paper residues in construction products," WRAP Project code: PAP009-011, The Waste \& Resources Action Programm, Banbury, UK, 2004. 
[8] P. Soroushian and Z. Shah, Reinforcement of Thin Cement Products with Recycled Wastepaper Fibers, College of Engineering, Michigan State University, 1993.

[9] A. H. Abdel-Kader and H. H. Darweesh, "Setting and hardening of agro/cement composites," BioResources, vol. 5, no. 1, pp. 43-54, 2010.

[10] R. Rocha Almeida, C. Henrique Soares Del Menezzi, and D. Eterno Teixeira, "Utilization of the coconut shell of babaçu (Orbignya sp.) to produce cement-bonded particleboard," Bioresource Technology, vol. 85, no. 2, pp. 159-163, 2002.

[11] P. C. de Araújo, L. M. Arruda, C. H. S. Del Menezzi, D. E. Teixeira, and M. R. de Souza, "Lignocellulosic composites from Brazilian giant bamboo (Guadua magna). Part 2: properties of cement and gypsum bonded particleboards," Maderas, vol. 13, no. 3, pp. 297-306, 2011.

[12] A. H. Basta, M. Z. Sefain, and I. El-Rewainy, "Role of some treatments on enhancing the eco-friendly utilization of lignocellulosic wastes in production of cement-fiber bricks," BioResources, vol. 6, no. 2, pp. 1359-1375, 2011.

[13] A. A. Erakhrumen, S. E. Areghan, M. B. Ogunleye, S. L. Larinde, and O. O. Odeyale, "Selected physico-mechanical properties of cement-bonded particleboard made from pine (Pinus caribaea M.) sawdust-coir (Cocos nucifera L.) mixture," Scientific Research and Essays, vol. 3, no. 5, pp. 197-203, 2008.

[14] J. M. Ferraz, C. H.S. del Menezzi, D. E. Teixeira, and S. A. Martins, "Effects of treatment of coir fiber and cement/fiber ratio on properties of cement-bonded composites," BioResources, vol. 6, no. 3, pp. 3481-3492, 2011.

[15] L. C. Roma Jr., L. S. Martello, and H. Savastano, "Evaluation of mechanical, physical and thermal performance of cementbased tiles reinforced with vegetable fibers," Construction and Building Materials, vol. 22, no. 4, pp. 668-674, 2008.

[16] Technical Association of the Pulp and Paper Industry, Fiber Length of Pulp by Classification, TAPPI T $233 \mathrm{~cm}-82$, TAPPI Press, Atlanta, Ga, USA, 1994.

[17] Technical Association of the Pulp and Paper Industry, Freeness of Pulp, TAPPI T 227 om-94, TAPPI Press, Atlanta, Ga, USA, 1994.

[18] Technical Association of the Pulp and Paper Industry, Kappa Number of Pulp, TAPPI T $236 \mathrm{~cm}-85$, TAPPI Press, Atlanta, Ga, USA, 1994.

[19] Technical Association of the Pulp and Paper Industry, Laboratory Beating of Pulp (PFI mill method), TAPPI T $248 \mathrm{~cm}-85$, TAPPI Press, Atlanta, Ga, USA, 1994.

[20] G. A. Smook and M. J. Kocurek, Eds., Handbook for Pulp and Paper Technologists, Joint Textbook Committee of the Paper Industry, Atlanta, Ga, usa, 1982.

[21] F. C. Jorge, C. Pereira, and J. M. F. Ferreira, "Wood-cement composites: a review," Holz als Roh-und Werkstoff, vol. 62, no. 5, pp. 370-377, 2004.

[22] J. V. De Figueiredo Latorraca, D. E. Teixeira, and D. C. Batista, "Overlay of eucalyptus urophylla cement-bonded particleboard for application as flooring panels," Forest Products Journal, vol. 59, no. 6, pp. 65-69, 2009.

[23] A. Miyatake, T. Fujii, Y. Hiramatsu, H. Abe, and M. Tonosaki, "Manufacture of wood strand-cement composite for structural purpose," in Wood-Cement Composites in Asia-Pacific Region, P. D. Evans, Ed., pp. 148-152, ACIAR, Canberra, Australia, 2002.

[24] E. Y. A. Okino, M. R. De Souza, M. A. E. Santana, M. V. D. S. Alves, M. E. De Sousa, and D. E. Teixeira, "Physico-mechanical properties and decay resistance of Cupressus spp. cementbonded particleboards," Cement and Concrete Composites, vol. 27, no. 3, pp. 333-338, 2005.

[25] E. Y. A. Okino, M. R. De Souza, M. A. E. Santana, M. V. D. S. Alves, M. E. De Sousa, and D. E. Teixeira, "Cementbonded wood particleboard with a mixture of eucalypt and rubberwood," Cement and Concrete Composites, vol. 26, no. 6, pp. 729-734, 2004.

[26] E. Y. A. Okino, M. R. Souza, M. A. E. Santana, M. E. Sousa, and D. E. Teixeira, "Cement-bonded particleboard of Hevea brasiliensis Müll. Arg. Revista Árvore, Viçosa-MG,” Müller Argoviensis Revista Árvore, vol. 28, no. 3, pp. 451-457, 2004.

[27] A. N. Papadopoulos, "Decay resistance of cement bonded oriented strand board," Journal of the Institute of Wood Science, vol. 18, no. 2, pp. 109-111, 2008.

[28] A. N. Papadopoulos, G. A. Ntalos, and I. Kakaras, "Mechanical and physical properties of cement-bonded OSB," Holz als Roh-und Werkstoff, vol. 64, no. 6, pp. 517-518, 2006.

[29] R. C. D. Santos, L. M. Mendes, F. A. Mori, and R. F. Mendes, "Use of candeia's (Eremanthus erythropappus) waste wood for wood-cement panels production," Cerne, vol. 14, no. 3, pp. 241-250, 2008.

[30] P. Soroushian, S. Marikunte, and J. P. Won, "Statistical evaluation of mechanical and physical properties of cellulose fiber reinforced cement composites," ACI Materials Journal, vol. 92, no. 2, pp. 172-180, 1995.

[31] C. H. S. D. Meneéis, V. G. De Castro, and M. R. De Souza, "Production and properties of a medium density woodcement boards produced with oriented strands and silica fume," Maderas, vol. 9, no. 2, pp. 105-115, 2007.

[32] E. J. Van Elten, "Properties, production and applications of cement bonded particle board (CBPB) and wood strand cement board," in Proceedings of the 10th International Inorganic Bonded Fiber Composites Conference (IIBCC '06), São Paulo, Brazil, November 2006.

[33] G. J. Van Elten, "Production of wood wool cement board and wood strand cement board (eltoboard) on one plant and applications of the products," in Proceedings of the 10th International Inorganic-Bonded Fiber Composites Conference (IIBCC '06), São Paulo, Brazil, November 2006.

[34] American Society for Testing and Materials, Standard Test Methods for Evaluating the Properties of Wood-Base Fiber and Particle Panel Materials, ASTM, Philadelphia, Pa, USA, 1985.

[35] SAS Institute Inc., SAS/STAT 9.1 User's Guide, SAS Institute, Cary, NC, USA, 2004.

[36] Bison Wood Cement Board. Bison-Report, p.10, 1978.

[37] CETRIS. Basic Properties of CETRIS Cement Bonded Particleboard, 2012, http://www.cetris.cz.

[38] NCL GROUP, Bison Panel Cement Bonded Particle BoardTechnical Hand Book, NCL Group, Hyderabad, India, 2012.

[39] VERSAROC. VERSAROC cement-bonded particleboard, 2012, http://architecturalproducts.com/downloads/Versaroc. $\% 20$ Catalog.pdf

[40] D. E. Teixeira, Evaluation of fiber refining and fractionating of recycled old corrugated containers (OCC) for wood-fiber cement boards, M.S. thesis, University of Idaho, Moscow, Russia, 1997.

[41] G. C. Silva, J. V. D. F. Latorraca, J. F. Do Carmo, and E. S. Ferreira, "Effect of minerals additives on the properties of wood cement-bonded particleboard," Revista Arvore, vol. 30, no. 3, pp. 451-456, 2006. 

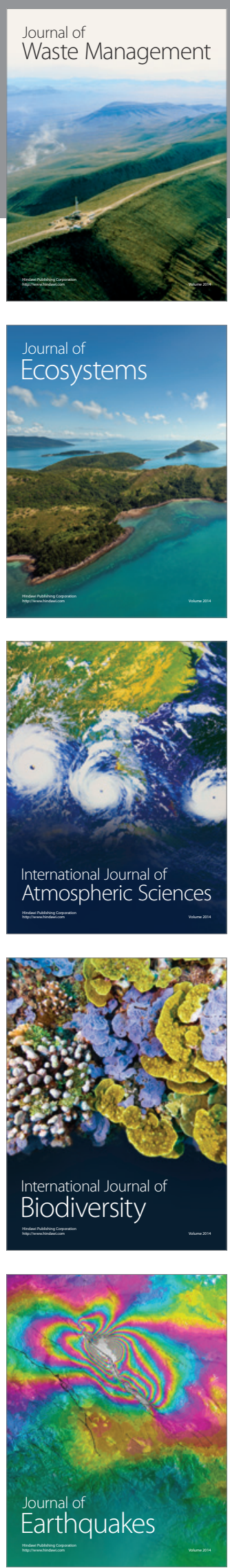
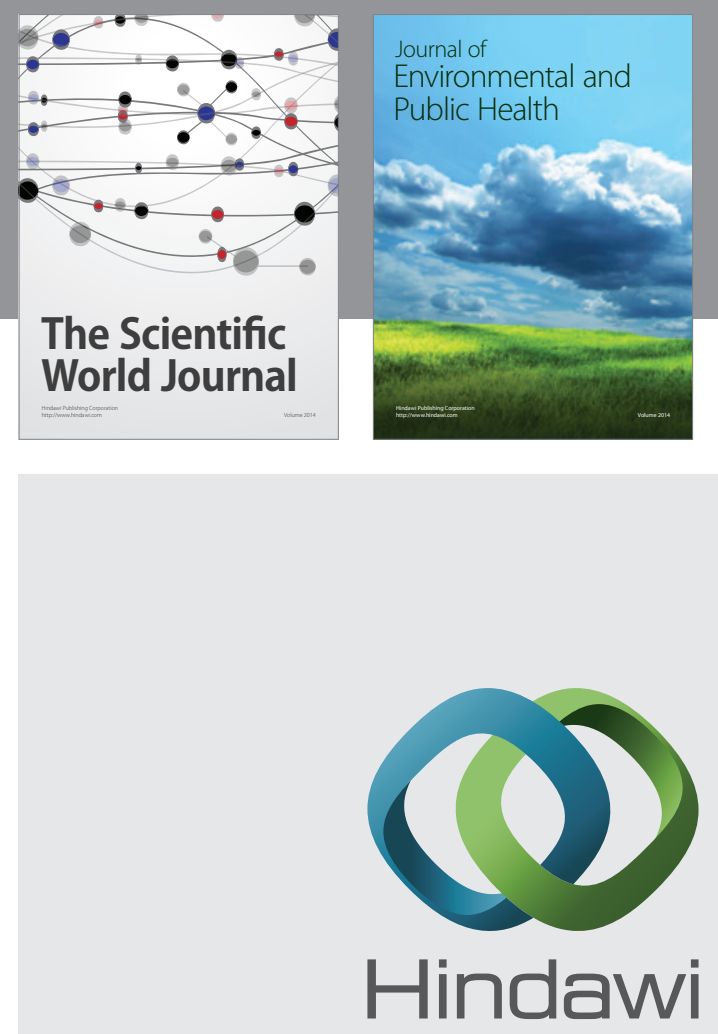

Submit your manuscripts at

http://www.hindawi.com
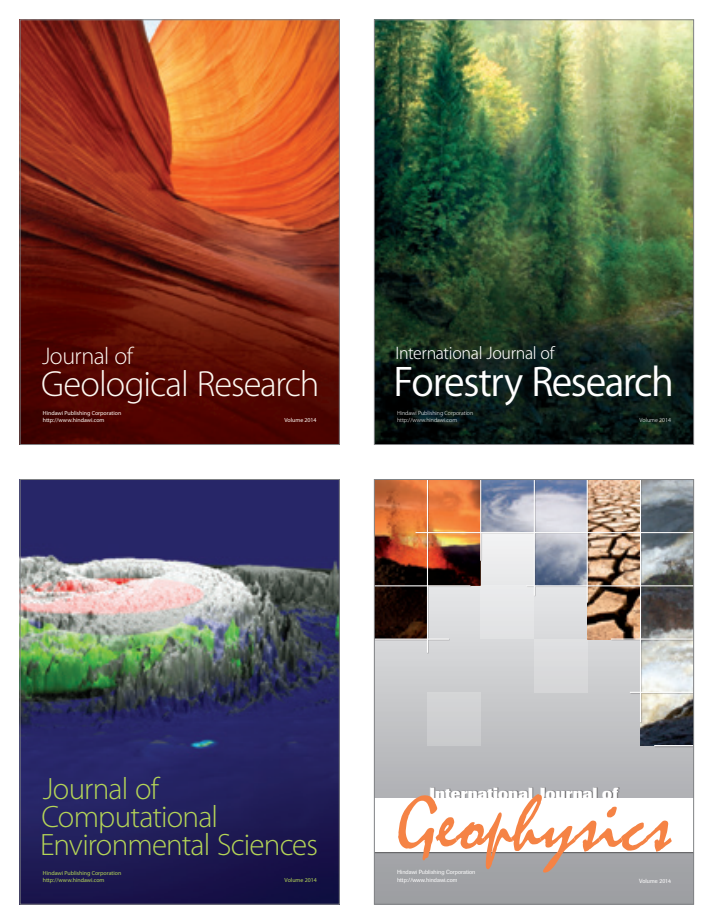
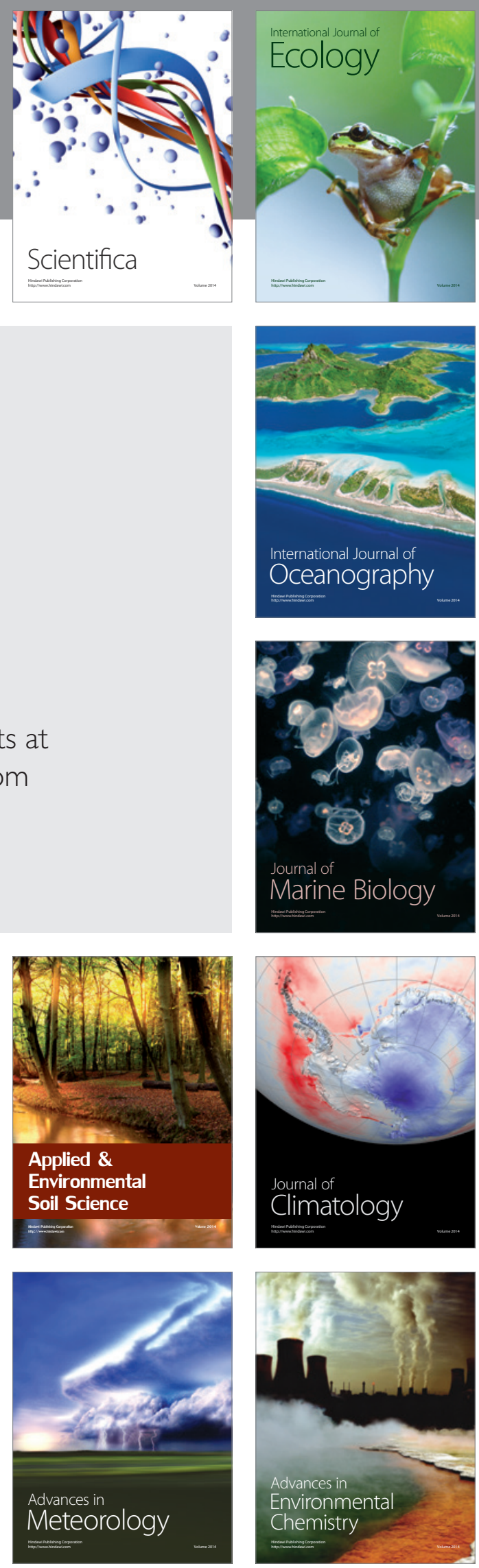